\title{
Coronary Heart Disease and Emotional Intelligence
}

\author{
Chrisanthy P. Vlachaki ${ }^{1} \&$ Katerina Maridaki-Kassotaki ${ }^{1}$ \\ ${ }^{1}$ Department of Home Economics and Ecology Harokopio University, Kallithea, Attica, Greece \\ Correspondence: Chrisanthy Vlachaki, 69 Keas st, Chalandri 15234, Attica, Greece. E-mail: cvlachaki@hua.gr
}

Received: July 21, 2013 Accepted: August 19, 2013 Online Published: September 23, 2013

doi:10.5539/gjhs.v5n6p156 URL: http://dx.doi.org/10.5539/gjhs.v5n6p156

\begin{abstract}
Background: Coronary Heart Disease (CHD) is associated with emotions, especially negative ones, namely anxiety and depression. Emotional Intelligence (EI) is a psychological model that consists of a variety of emotional skills.

Aims: The aim of the present study was to examine the relation between different dimensions of Emotional Intelligence and coronary heart disease.

Methods: A total of 300 participants were studied during a 3-year period in an attempt to partially replicate and further expand a previous study conducted in Greece among CHD patients, which indicated a strong association between certain dimensions of Emotional Intelligence and the incidence of CHD. All participants completed a self-report questionnaire, assessing several aspects of Emotional Intelligence.
\end{abstract}

Findings: The results showed that there is a link between the regulation of emotions and the occurrence of CHD.

Conclusions: The evidence reported in the present study makes stronger the claim that EI plays a significant role in the occurrence of CHD.

Keywords: coronary, heart disease, emotion, emotional intelligence, regulation, risk factor

\section{Introduction}

While there is a great amount of interesting scientific research indicating that the autonomic nervous system may be a major component of the emotion response, a simple model that can guide a physician in managing the emotions of a person in favor of his health has not been produced yet (Kreibig, 2010). Numerous studies have found, however, that negative emotions and thoughts may cause disease along with other important risk factors, while positive emotions can improve health and eliminate disease. Most risk factors that drive Coronary Heart Disease (CHD) have genetic, environmental, physiologic and behavioral components (Kones, 2011). The disease can be influenced by negative emotions, such as stress, anger, anxiety, resentment and depression (Das \& O'Keefe, 2006; Sirois \& Burg, 2003). There is a very significant body of knowledge regarding the relation between health and emotions (Gross, 2013; Kubzansky, 2011). However, this relation has not been thoroughly evaluated within the context of a psychological model.

The present study attempted to partially replicate and further enhance a previous one conducted among fifty-six Greek CHD patients which examined the relationship between understanding of emotions, namely self-emotion appraisal, others' emotion appraisal, use of emotions and regulation of emotions and coronary heart disease, within the psychological context of Emotional Intelligence (Kravvariti, Maridaki-Kassotaki, \& Kravvaritis, 2010). The researchers have demonstrated that self-reported aspects of Emotional Intelligence (EI), such as use of emotions and regulation of emotions, are associated with incidence of coronary heart disease. The dimension "use of emotion" or, in other words, "utilization of emotions" refers to the individual's ability to utilize and direct emotions in order to improve his performance. A person who is highly capable in this dimension would be able to encourage himself and move towards positive directions. A person who is highly capable in the dimension "regulation of emotion" would have better control of his emotions.

The present study was an attempt to replicate the above study using a greater sample of patients (approximately 3 -fold increase in sample size) and an additional number of CHD risk factors, such as hyperlipidemia, diabetes mellitus, and demographic characteristics, such as marital status. The highly significant risk factors for developing coronary heart disease may act as confounders and they had to be accounted for and managed in accordance to the Kravvariti's study. 
Coronary heart disease is a significant public health issue due to its high prevalence and mortality rate (National Institutes of Health, 2012). A number of clinical and experimental studies have indicated that strong emotions, especially negative emotions, such as anger, hostility, depression and stress precipitate coronary heart disease. Coronary heart disease patients, for example, have difficulty in coping with stress and depression and experience negative emotions, like anger or frustration. Positive emotions, on the other hand, especially hope, contribute to health benefits and lead to lower levels of coronary heart disease (Tunstall-Pedoe, 2001; Carr, 2008; Koelsch, Enge \& Jentschke, 2012).

Among the negative emotions, stress is one of the most predisposing factors of people with coronary heart disease (Glozier et al., 2013). There are studies showing that stress caused by conflicts in close relationships (family, friends, coworkers, spouses) may predict myocardial infarction for both genders (De Vogli, Chandola \& Marmot, 2007). Similarly, stressful marital relationships may triple the risk for recurrent coronary heart disease events (Orth-Gomér et al., 2000; Orth-Gomér \& Leineweber, 2005). Further, job strain along with lack of effort-reward policies may cause coronary heart disease for men and women (Kuper \& Marmot, 2003; Kuper et al., 2002; Eaker et al., 2004).

Moreover, another negative psychological state such as depression is associated with coronary heart disease (Compare et al., 2013). Numerous studies have confirmed the prominence of depressive symptoms and major depression in patients with coronary heart disease (Hemingway \& Marmot, 1999; Panagiotakos et al., 2002; Goldston \& Baillie, 2008; Rozanski, Blumenthal, \& Kaplan, 1999). Patients with depression have increased platelet reactivity, decreased heart variability and increased inflammatory markers, such as C-reactive protein, which are all risk factors for coronary heart disease (Reichenberg et al., 2001). Further, there is evidence to show that the continued presence of depression after recovery of myocardial infarction increases the risk of death to 17 percent within 6 months after the event (Frasure-Smith, Lespérance, \& Talajic, 1993).

Further, anger and hostility have been shown to influence risk of coronary heart disease (Kent \& Shapiro, 2009; Chida \& Steptoe, 2009). On the other hand, positive emotions, for example optimism is associated with reduced risk for myocardial infarction and coronary heart disease mortality in the Women's Health Initiative study (Tindle et al., 2009), as well as the frequent expression of positive emotions is associated with decreased incidence of coronary heart disease (Saxena et al., 2012; Low, Thurston, \& Matthews, 2010). Increased frequency of positive feelings and decreased frequency of depressive symptoms might be indicated as a preventive factor for coronary heart disease (Davidson et al., 2010). In a recent study, Denollet (2010) indicated that suppression of emotions is a major risk factor for coronary heart disease. He managed to illustrate that cardiac patients who tend to inhibit the expression of their emotions have a higher death rate than other patients (Denollet et al., 1996).

As stated above, there is a great amount of evidence attesting to a link between coronary heart disease and psychological states like depression, anger, anxiety, stress, etc. Little evidence, however, has been provided thus far attesting to the link between coronary heart disease and emotions within a psychological model, like that of Emotional Intelligence proposed by recent theorists (Mayer \& Salovey, 1997; Goleman, 1995; Petrides, 2001). In their theories, Emotional Intelligence (EI) has been characterized as "the ability to perceive emotions, to access and generate emotions so as to assist thought, to understand emotions and emotional knowledge, and to reflectively regulate emotions so as to promote emotional and intellectual growth". The term EI was first used in the doctoral thesis of Wayne Payne (1986), entitled: "A Study of Emotion: Developing Emotional Intelligence", where he defined EI as the ability to express emotions openly. In 1995, Daniel Goleman published his book "Emotional Intelligence: Why It Can Matter More than IQ" and made the term widely used.

There are two different constructs of EI, trait EI and ability EI. Trait EI concerns emotion-related self-perceptions measured by self-report questionnaires and ability EI concerns emotion-related cognitive abilities that ought to be measured by maximum performance questionnaires (Petrides \& Furnham, 2001). The maximum performance questionnaire is defined by the work of Mayer and his colleagues in 1999. The later developed items that can be responded to correctly or incorrectly, in contrast to self-reported items (Mayer, Salovey, \& Caruso, 1999; Mayer et al., 2003).

The aforementioned study conducted in Greece has been, so far, the only study, which has examined the above issue. The present study was designed to partially replicate the above study in a greater sample of Greek patients. In addition, it sought to examine the relation of a number of atherosclerotic risk factors, as well as demographic characteristics to CHD incidence. The major atherosclerotic risk factors and some demographic characteristics are well-known prognostic factors for the disease. If they are not measured appropriately, they may lead to bias and distort the magnitude of the relationship between Emotional Intelligence and coronary heart disease. For that 
reason, they were accounted as confounding variables.

Based on previous relevant studies, the hypothesis made in the study was that individuals who suffer from coronary heart disease would have low performance in the tests assessing dimensions of Emotional Intelligence, namely self-emotion appraisal, others' emotion appraisal, use of emotions and regulation of emotions. Furthermore, it is hypothesized that various dimensions of Emotional Intelligence may be good predictors of coronary heart disease and should be accounted for as potential risk factors, such as smoking or family history of $\mathrm{CHD}$, in future research.

\section{Method}

The data were gathered from the General Hospital of Attica "KAT" in Athens, Greece, during a 3-year period. Written informed consents were obtained from all studied subjects. The study was funded by the Onassis Foundation and approval to be conducted was granted by the Authorities and Scientific board of the above Hospital.

\subsection{Participants}

Three hundred (300) hospitalized patients - 150 with and 150 without CHD - were recruited for participation in this study. CHD patients were hospitalized in the department of Cardiology of the General Hospital of Attica "KAT" and had a documented history of myocardial infarction, or angiographic evidence of coronary artery disease and/or positive treadmill ECG test (Scanlon et al., 1999). Non-CHD patients were assessed free of significant CHD and were hospitalized in the department of Orthopedics of the above hospital. The characteristics of the subjects measured, included demographics, family history of CHD and atherosclerotic risk factors, such as hyperlipidemia, diabetes mellitus, hypertension, smoking, obesity, with the respective data been collected from their medical files. Both groups consisted of hospitalized patients, because they experience more stress, fear of the unknown and embarrassment during hospitalization when compared to a non-hospitalized group of people (Wilson-Barnett, 2008).

\subsection{Measures}

The Greek version of the self-report Wong \& Law Emotional Intelligence Scale (WLEIS) was used in order to assess Emotional Intelligence. It consists of 16 items falling into four categories, each category representing a different dimension of Emotional Intelligence and comprising four items. More specifically, the self-emotion appraisal dimension refers to an individual's self-perceived ability to understand his emotions (e.g., "I really understand what I feel"). The others' emotion appraisal dimension refers to a person's tendency to be able to perceive other peoples' emotions (e.g., "I have good understanding of the emotions of people around me"). The use of emotions dimension concerns the self-perceived tendency to motivate one self to enhance performance (e.g. "I am a self-motivated person"). The regulation of emotions dimension concerns individuals' perceived ability to regulate and control their own emotions (e.g., "I am quite capable of controlling my own emotions"). Each item was rated on a seven point Likert scale ( $1=$ strongly disagree, to $7=$ strongly agree $)$. The validity and reliability of the Greek version of the WLEIS instrument have been established by Kafetsios and Zampetakis (2008). Cronbach Alpha reliability coefficients of the Greek version of the WLEIS factors in the present study were found to be $0.70,0.71,0.78$, and 0.78 for self-emotion appraisal, others' emotion appraisal, use of emotions and regulation of emotions, respectively. Although Cronbach's alpha values of 0.7-0.8 are generally considered acceptable, they still have a $20-30 \%$ chance of not measuring the concepts under study and affect the findings. A test with a reliability of 0.7 means that $30 \%$ of its variance is made up of errors.

\subsection{Statistical Analysis}

Normality of distribution was assessed using the Kolmogorov-Smirnov test. A power analysis was used to determine the sample size. Comparison between two groups was performed with Student's $t$ tests or Mann-Whitney U tests, whether they follow the normal distribution or not. Pearson's Chi-square calculations were used to compare qualitative variables represented as frequencies. Binary logistic regression was used to determine the variables that independently contributed to the presence of CHD. Odds ratio (OR) and $95 \%$ confidence interval (CI) were calculated. All tests were two-sided and $\mathrm{P}<0.05$ was considered statistically significant. Statistical analyses were performed using SPSS 17.0 (IBM SPSS, Inc., Chicago, USA).

\section{Results}

Table 1 shows the demographic characteristics and the atherosclerotic risk factors for the two groups (CHD patients and non-CHD patients). Three hundred (300) hospitalized patients - 150 with and 150 without CHD participated in this study. The mean age of CHD participants was 69.9 years $(\mathrm{SD}=9.37)$ and $74.7 \%$ of them were males. The mean age of non-CHD patients was 69.1 years $(\mathrm{SD}=10.86)$ and $74.7 \%$ of them were males. 
They did not differ reliably from that of CHD patients. Most of the subjects were married $(77.3 \%$ of CHD patients and $74.7 \%$ of non-CHD patients). The prevalence of atherosclerotic risk factors was significantly higher in CHD patients, as expected. Significantly more CHD subjects suffered from hyperlipidemia $(\mathrm{p}<0.001)$, diabetes mellitus $(\mathrm{p}<0.001)$ and obesity $(\mathrm{p}=0.011)$, as compared to non-CHD patients.

Table 1. Absolute and mean values of demographic characteristics and atherosclerotic risk factors between the two groups, CHD and non-CHD patients (pts)

\begin{tabular}{llll}
\hline & CHD pts (n=150) & Non-CHD pts (n=150) & P-value \\
\hline Age (years) & $69,85 \pm 9,73$ & $69,10 \pm 10,86$ & 0,708 \\
Gender (male) & $112(74,7 \%)$ & $112(74,7 \%)$ & 1,000 \\
Marital status & & & 0,494 \\
$\quad$ Married & $116(77,3 \%)$ & $112(74,7 \%)$ & \\
$\quad$ Not married & $13(8,7 \%)$ & $9(6,0 \%)$ & \\
$\quad$ Widow & $16(10,7 \%)$ & $24(16,0 \%)$ & \\
$\quad$ Divorced & $5(3,3 \%)$ & $5(3,0 \%)$ & \\
Risk factors & & & $<\mathbf{0 , 0 0 1}$ \\
$\quad$ Hyperlipidemia & $102(68,0 \%)$ & $39(26,0 \%)$ & $<\mathbf{0 , 0 0 1}$ \\
$\quad$ Diabetes & $44(29,3 \%)$ & $18(12,0 \%)$ & 1,000 \\
Hypetension & $92(61,3 \%)$ & $92(61,3 \%)$ & 0,359 \\
Family history of CHD & $36(24,0 \%)$ & $43(28,7 \%)$ & 0,897 \\
Smoking & $41(27,3 \%)$ & $40(26,7 \%)$ & $\mathbf{0 , 0 1 1}$ \\
$\quad$ Obesity & $41(27,3 \%)$ & $23(15,3 \%)$ & \\
\hline
\end{tabular}

Data are mean $\pm S D$ and number (\%).

Table 2 presents the performance in each of the four dimensions of the EI test for the two groups. The patients with CHD had significantly lower performance in all the examined dimensions of Emotional Intelligence compared to non-CHD patients $(\mathrm{p}<0.001)$. However, no significant difference was observed in hypertension, family history of CHD and smoking.

Table 2. Absolute and mean values of performance of patients in each of four dimensions of the Emotional Intelligence (EI) test between the two groups, CHD and non-CHD patients (pts)

\begin{tabular}{llll}
\hline \multicolumn{5}{c}{ CHD pts (n=150) } & Non-CHD pts (n=150) & $P$-value \\
\hline Dimensions of Emotional Intelligence (EI) & & \\
1. Self-Emotion Appraisal & $5,55 \pm 1,07$ & $6,29 \pm 0,74$ & $<\mathbf{0 , 0 0 1}$ \\
2. Others' Emotion Appraisal & $5,40 \pm 1,11$ & $6,21 \pm 0,72$ & $<\mathbf{0 , 0 0 1}$ \\
3. Use of Emotions & $5,32 \pm 1,27$ & $6,30 \pm 0,68$ & $<\mathbf{0 , 0 0 1}$ \\
4. Regulation of Emotions & $4,97 \pm 1,22$ & $6,30 \pm 0,73$ & $<\mathbf{0 , 0 0 1}$ \\
\hline
\end{tabular}

Data are mean $\pm S D$ and number (\%).

In order to examine whether emotions may be good predictors of CHD, a binary logistic regression analysis was conducted on the data (see Table 3). In this analysis, the outcome measure was the presence of CHD. The independent variables were the four components of the WLEIS questionnaire and the classical atherosclerotic risk factors, such as hyperlipidemia, diabetes mellitus, hypertension, family history of CHD, smoking and obesity. The well-established risk factors, namely hypertension, family history for CHD and smoking, were included in the model, even though they were not found to have a significant difference in their mean values between the two groups, because they are potential confounders according to the bibliography (Brenner \& 
Blettner, 1997). In order to evaluate the utility of the statistical model, the overall percentage accuracy rate was estimated. The percentage of accuracy was produced by SPSS at the last step in the Classification Table. An accuracy rate of $82.7 \%$, suggests that the model is useful, because it predicts accurately $82.7 \%$ of cases.

Table 3. Logistic Regression Analyses for the effect of emotional and atherosclerotic risk factors on CHD

\begin{tabular}{|c|c|c|c|c|}
\hline & B & $\begin{array}{l}\text { Odds Ratio } \\
\operatorname{Exp}(B)\end{array}$ & $\begin{array}{l}\text { 95\% Confidence } \\
\text { Interval }\end{array}$ & $P$-value \\
\hline \multicolumn{5}{|c|}{ Dimensions of Emotional Intelligence (EI) } \\
\hline Self-Emotion Appraisal & 0.502 & 1.652 & $0.866-3.152$ & 0.128 \\
\hline Others' Emotion Appraisal & -0.522 & 0.593 & $0.342-1.029$ & 0.063 \\
\hline Use of Emotions & -0.136 & 0.873 & $0.501-1.521$ & 0.632 \\
\hline Regulation of Emotions & -1.428 & 0.240 & $0.138-0.416$ & $<0.001$ \\
\hline \multicolumn{5}{|l|}{ Risk factors } \\
\hline Hyperlipidemia & 1.947 & 7.011 & $3.625-13.560$ & $<0.001$ \\
\hline Diabetes & 1.249 & 3.485 & $1.520-7.990$ & 0.003 \\
\hline Hypertension & 0.187 & 1.206 & $0.620-2.345$ & 0.582 \\
\hline Family history of CHD & -0.299 & 0.742 & $0.351-1.569$ & 0.434 \\
\hline Smoking & 0.483 & 1.621 & $0.791-3.321$ & 0.187 \\
\hline Obesity & 0.418 & 1.519 & $0.703-3.282$ & 0.288 \\
\hline
\end{tabular}

The Cox \& Snell R Square and the Nagelkerke R Square values provide an indication of the amount of variation in the dependent variable. These are described as pseudo $\mathrm{R}$ square. These values are 0.433 and 0.578 respectively, suggesting that between $43.3 \%$ percent and $57.8 \%$ percent of the variability is explained by this set of variables used in the model.

As presented in Table 3, regulations of emotions was significant at the 0.001 level thus showing decrease in the odds of the disease by $76 \%$ for one unit increase in the relevant score. Patients with lower ability to regulate their emotions have about $76 \%$ higher likelihood of suffering from CHD (odds ratio $=0.240, p<0.001$ ). Participants with hyperlipidemia have $601.1 \%$ higher likelihood of suffering from CHD (odds ratio $=7.011, \mathrm{p}<0.001$ ). Furthermore, participants with diabetes mellitus have $248.5 \%$ higher likelihood of being diagnosed with CHD (odds ratio $=3.485, \mathrm{p}=0.003$ ). Self-Emotion Appraisal, Others' Emotion Appraisal, Use of Emotion, hypertension, family history of CHD and smoking and obesity did not appear to play a part in the occurrence of the disease, since they failed to reach significance ( $\mathrm{p}$-value $>0.05$ ). Therefore, Regulation of Emotions, hyperlipidemia and diabetes mellitus are significant predictors of CHD.

\section{Discussion}

The purpose of this study was to examine the relationship between coronary heart disease and four dimensions of Emotional Intelligence, namely self-emotion appraisal, others' emotion appraisal, use of emotions and regulation of emotions. Most importantly, the present data are congruent and expand evidence reported in a previous study conducted in Greece, which has established the relation between coronary heart disease and regulation of emotions (Kravvariti, Maridaki-Kassotaki, \& Kravvaritis, 2010). In the present study, as mentioned above, the researchers attempted to replicate these findings and indicated that decreased ability to regulate emotions is associated with the incidence of coronary heart disease.

Moreover, the obtained data suggest that people with CHD may suffer from hyperlipidemia and diabetes too. These results are in line with numerous previous studies showing that patients with diabetes have higher risk of developing CHD than people without diabetes (Bays, 2012; Zhang et al., 2012; Sousa et al., 2011). According to several studies, the prevalence of hyperlipidemia in CHD patients is higher compared to that of age-matched controls without CHD (Simon, 2012; Watkins, 2004). The findings of numerous studies support that there is a negative relationship between increased levels of Emotional Intelligence and physical health (Tsaousis \& Nikolaou, 2005; Martins, Ramalho \& Morin, 2010; Schutte et al., 2007). However, there is no evidence to indicate a link between Emotional Intelligence and hyperlipidemia or diabetes mellitus. 
The core finding of the present study was that the regulation of emotions is a good predictor of coronary heart disease. More specifically, the occurrence of coronary heart disease is related to decreased ability to regulate emotions. In the present study, the regulation of emotions reflected the ability to control temper and one's emotions as well as the ability to handle with difficulties and one's anger. The reported evidence, therefore, shows that coronary heart disease patients have difficulty in controlling their anger and temper, as well as their emotions. The present findings are in line with previous evidence showing that specific negative emotions such as anger inhibition may increase the risk of coronary heart disease, whereas control of emotions may be protective (Graves, 1994; Harburg, 2003). They also support the claim that anger, hostility or other uncontrolled negative emotions, may cause damage to the cardiovascular system through physiological alterations and increase the risk of a cardiac event (Haines, Cooper, \& Meade, 2001; Krantz \& McCeney, 2002; Steptoe, 2000).

Previous research support that there is a link between coronary heart disease and Type A behavior pattern (Kent \& Shapiro, 2009). People with type A behavior seem to be hostile, aggressive, impatient and competitive. The present findings relate to the old Type A theories, as they reflect that coronary heart disease patients have low ability of regulation of emotions and experience uncontrolled anger and temper.

By and large, the present findings expand previous evidence showing that coronary heart disease patients have difficulties in regulating their emotions. In relation to this, relevant evidence shows that forms of emotion regulation such as reappraisal of emotions and suppression of emotions increases or decreases the levels of C-reactive protein respectively, the C-reactive protein being an inflammatory marker and one of the most well-established risk factors for coronary heart disease (Gross, 2013). In a recent study conducted on more than one thousand participants who were followed up for 13 years, it was found that the successful regulation of emotions is related to decreased risk for coronary heart disease, even when controlling for traditional coronary risk factors (Kubzansky, 2011). Similarly, several other studies have demonstrated that emotion regulation may promote cardiovascular health, reduce the risk for coronary heart disease and contribute to greater well-being (Côté, 2010; Kubzansky \& Thurston, 2007; Rozanski et al., 2005; Pennebaker, 1995; Urry \& Gross, 2010; Cornelius, 2001; Bushman, 2002).

\section{Limitations of the Study}

The first and most obvious limitation of the present study is the fact that there was used a self-reported measurement of Emotional Intelligence. It is possible that it mirrored the relationship between perceived Emotional Intelligence (not objective) and coronary heart disease. However, even so, it is still an important finding. Additionally, many of the studies cited above appear to have several confounding variables that are likely to affect the findings. This represents a methodological flaw in some studies. The same applies to the current study. The major atherosclerotic risk factors and some demographic characteristics are well-known prognostic factors for the disease. If they are not measured appropriately, they may lead to bias and distort the magnitude of the relationship between Emotional Intelligence and coronary heart disease. The well-established risk factors, namely hypertension, family history for CHD and smoking, were included in the model, even though they were not found to have a significant difference in their mean values between the two groups, because they are potential confounders according to the bibliography. Other risk factors that were not taken into account may have influenced the findings. Finally, the alpha scores only indicate acceptable reliability. They have a $20-30 \%$ chance of not measuring the concepts under study and affect the findings.

\section{Conclusions}

A particularly interesting finding of the present study was that a dimension of Emotional Intelligence, namely regulation of emotions, is a good predictor of coronary heart disease. CHD patients have lower abilities of understanding, using and regulating emotions, compared to non-CHD patients, which eventually have an impact on their health. The study of Kravvariti and colleagues was reproduced as closely as possible in a greater sample of patients and was further enhanced with additional risk factors and demographic characteristics. Based on the present findings, we may claim that emotion regulation plays a determinant role in attaining cardiovascular health. Further research, however, is needed in order to identify which emotion regulation strategies (Gross, 1998) are associated with the occurrence of coronary heart disease.

\section{Implications of the Findings}

The present findings may have several practical implications for both research and health care settings. The fact that a dimension of Emotional Intelligence predicts coronary heart disease demands that health care providers should begin to develop programs to foster Emotional Intelligence in CHD patients. If, for instance, patients with coronary heart disease are trained to regulate successfully their emotions with the use of appropriate training programs, their health may be improved. As Emotional Intelligence is teachable and learnable (Goleman, 1998), 
cardiologists and psychologists should endeavor to teach the principles of Emotional Intelligence to patients. The five strategies, for example, of emotion regulation proposed by Gross (1998) may be used to develop such a program. Future research should focus on the examination of the effectiveness of such training programs.

\section{References}

Bays, H. E. (2012). Adiposopathy, diabetes mellitus, and primary prevention of atherosclerotic coronary artery disease: treating "sick fat" through improving fat function with antidiabetes therapies. The American Journal of Cardiology, 110(9), 4B-12B. http://dx.doi.org/10.1016/j.amjcard.2012.08.029

Brenner, H., \& Blettner, M. (1997). Controlling for continuous confounders in epidemiologic research. Epidemiology, 8(4), 429-434.

Bushman, B. (2002). Does venting anger feed or extinguish the flame? Catharsis, rumination, distraction, anger, and aggressive responding. Personality and Social Psychology Bulletin, 28, 724-731.

Carr, A. (2008). Positive psychology. New York: Routledge; Spl Indian Reprint.

Chida, Y., \& Steptoe, A. (2009). The association of anger and hostility with future coronary heart disease: a meta-analytic review of prospective evidence. Journal of the American College of Cardiology, 53(11), 936-946. http://dx.doi.org/10.1016/j.jacc.2008.11.044

Compare, A., Zarbo, C., Manzoni, G. M., Castelnuovo, G., Baldassari, E., Bonardi, A., Callus, E., \& Romagnoni, C. (2013). Social support, depression, and heart disease: a ten year literature review. Frontiers in Psychology, 1(4), 384. http://dx.doi.org/10.3389/fpsyg.2013.00384

Cornelius, R. R. (2001). Crying and catharsis. In A. J. J. M. Vingerhoets \& R. R. Cornelius (Eds.), Adult crying: a biopsychosocial approach (pp. 199-211). Hove, United Kingdom: Brunner Routledge.

Côté, S., Gyurak, A., \& Levenson, R. W. (2010). The ability to regulate emotion is associated with greater well-being, income, and socioeconomic status. Emotion, 10(6), 923-933. http://dx.doi.org/10.1037/a0021156

Das, S., \& O' Keefe, J. H. (2006). Behavioral cardiology: recognizing and addressing the profound impact of psychosocial stress on cardiovascular health. Current Atherosclerosis Reports, 8(2), 111-118.

Davidson, K. W., Mostofsky, E., \& Whang, W. (2010). Don’t Worry, Be Happy: Positive Affect and Reduced 10-year Incident Coronary Heart Disease: The Canadian Nova Scotia Health Survey. European Heart Journal, 31(9), 1065-70. http://dx.doi.org/10.1093/eurheartj/ehp603

Davis, A. (2012). Examining Gender and Socio-Economic Status on the Emotional Intelligence of Early Adolescents. PCOM Psychology Dissertations. Paper 211. Retrieved from http://digitalcommons.pcom.edu/psychology_dissertation

Denollet, J., Sys, S. U., Stroobant, N., Rombouts, H., Gillebert, T. C., \& Brutsaert, D. L. (1996). Personality as independent predictor of long term mortality in patients with coronary heart disease. Lancet, 347(8999), 417-421.

Denollet, J., Gidron, Y. Y., Vrints, C. J., \& Conraads, V. (2010). Anger, suppressed anger, and risk of adverse events in patients with coronary artery disease. American Journal of Cardiology, 105, 1555-1560. http://dx.doi.org/10.1016/j.amjcard.2010.01.015

De Vogli, R., Chandola, T., \& Marmot, M. G. (2007). Negative aspects of close relationships and heart disease. Archives of Internal Medicine, 167, 1951-1957.

Eaker, E. D., Sullivan, L. M., Kelly-Hayes, M., D'Agostino, R. B., \& Benjamin, E. J. (2004). Does job strain increase the risk for coronary heart disease or death in men and women? The Framingham Offspring Study. American Journal of Epidemiology, 159, 950-958.

Everson, S. A., Lynch, J. W., Chesney, M. A., Kaplan, G. A., Goldberg, D. E., \& Shade, S. B., Expert Committee on the Diagnosis and Classification of Diabetes Mellitus. (1997). Report of the Expert Committee on the Diagnosis and Classification of Diabetes Mellitus. Diabetes Care, 20, 1183-197.

Frasure-Smith, N., Lespérance, F., \& Talajic, M. (1993). Depression following myocardial infarction: Impact on 6-month survival. JAMA, 270(15), 1819-1825.

Genest, J. J. Jr., Martin-Munley, S. S., McNamara, J. R., Ordovas, J. M., Jenner, J., Myers, R. H., ... Schaefer, E. J. (1992). Familial lipoprotein disorders in patients with premature coronary artery disease. Circulation, 85 , 2025-2033. 
Glozier, N., Tofler, G. H., Colquhoun, D. M., Bunker, S. J., Clarke, D. M., Hare, D. L., ... Branagan, M. G. (2013). Psychosocial risk factors for coronary heart disease. The Medical Journal of Australia, 199(3), $179-80$.

Goldston, K., \& Baillie, A. J. (2008). Depression and coronary heart disease: A review of the epidemiological evidence, explanatory mechanisms and management approaches. Clinical Psychology Review, 28, 288-306.

Goleman, D. (1995). Emotional Intelligence. New York, NY: Bantam Books.

Goleman, D. (1998). Working with emotional intelligence. New York: Bantam Books.

Graves, P. L., Mead, L. A., Wang, N. Y., Liang, K., \& Klag, M. J. (1994). Temperament as a potential predictor of mortality: evidence from a 41year prospective study. Journal of Behavioral Medicine, 17, 111-126.

Gross, J. J. (2013). Emotion Regulation: Taking Stock and Moving Forward. Emotion. Advance online publication. http://dx.doi.org/10.1037/a0032135

Gross, J. J. (1998). The emerging field of emotion regulation: An integrative review. Review of General Psychology, 2, 271-299.

Haines, A., Cooper, J., \& Meade, T. W. (2001). Psychological characteristics and fatal ischaemic heart disease. Heart (British Cardiac Society), 85, 385-389.

Harburg, E., Julius, M., Kaciroti, N., Gleiberman, L., \& Schork, M. A. (2003). Expressive/ suppressive anger-coping responses, gender, and types of mortality: a 17-year follow-up (Tecumseh, Michigan, 1971-1988). Psychosomatic Medicine, 65, 588-597.

Hemingway, H., \& Marmot, M. (1999). Psychological factors in the aetiology and prognosis of coronary heart disease: systematic review of prospective cohort studies. BMJ, 318, 1460-1467.

Hosmer, D. W., \& Lemeshow, S. (1989). Applied logistic regression. New York: Wiley Interscience.

Kafetsios, K., \& Zampetakis, L. (2008). Emotional Intelligence and job satisfaction: Testing the mediatory role of positive and negative affect at work. Personality and Individual Differences, 44, 710-720.

Kannel, W. B., \& McGee, D. L. (1979). Diabetes and cardiovascular risk factors: the Framingham study. Circulation, 59, 8-13.

Katon, W. J., Von Korff, M., Lin, E. H., Simon, G., Ludman, E., Russo, J., .. Bush, T. (2004). The Pathways Study: a randomized trial of collaborative care in patients with diabetes and depression. Archives of General Psychiatry, 61, 1042-1049.

Kent, L. K., \& Shapiro, P. A. (2009). Depression and related psychological factors in heart disease. Harvard Review of Psychiatry, 17(6), 377-388. http://dx.doi.org/10.3109/10673220903463333.

Koelsch, S., Enge, J., \& Jentschke, S. (2012). Cardiac Signatures of Personality. PLoS One, 7(2), e31441. http://dx.doi.org/10.1371/journal.pone.0031441

Kones, R. (2011). Primary prevention of coronary heart disease: integration of new data, evolving views, revised goals, and role of rosuvastatin in management. A comprehensive survey. Drug Design, Development and Therapy, 5, 325-380. http://dx.doi.org/10.2147/DDDT.S14934

Krantz, D. S., \& Manuck, S. B. (1984). Acute psychophysiologic reactivity and risk of cardiovascular disease: A review and methodologic critique. Psychological Bulletin, 96, 435-464.

Kravvariti, E., Maridaki-Kassotaki, K., \& Kravvaritis, E. (2010). Emotional Intelligence and Coronary heart disease: How close is the link?. Global Journal of Health Science, 1(2), 127-137.

Kreibig, S. D. (2010). Autonomic nervous system activity in emotion: a review. Biological Psychology, 84(3), 394-421. http://dx.doi.org/10.1016/j.biopsycho.2010.03.010

Kubzansky, L. D., Park, N., Peterson, C., Vokonas, P., \& Sparrow, D. (2011). Healthy psychological functioning and incident coronary heart disease: The importance of self-regulation. Archives of General Psychiatry, 68, 400-408. http://dx.doi.org/10.1001/archgenpsychiatry.2011.23

Kubzansky, L. D., \& Thurston, R. C. (2007). Emotional Vitality and Incident Coronary Heart Disease: Benefits of Healthy Psychological Functioning. Archives of General Psychiatry, 64(12), 1393-1401.

Kuper, H., \& Marmot, M. (2003). Job strain, job demands, decision latitude, and risk of coronary heart disease within the Whitehall II study. Journal of Epidemiology and Community Health, 57, 147-153.

Kuper, H., Singh-Manoux, A., Siegrist, J., \& Marmot, M. (2002). When reciprocity fails: effort-reward 
imbalance in relation to coronary heart disease and health functioning within the Whitehall II study. Occupational and Environmental Medicine, 59, 777-784.

Low, C. A., Thurston, R. C., \& Matthews, K. A. (2010). Psychosocial factors in the development of heart disease in women: current research and future directions. Psychosomatic Medicine, 72(9), 842-54. http://dx.doi.org/10.1097/PSY.0b013e3181f6934f

Martins, A., Ramalho, N., \& Morin, E. (2010). A comprehensive meta-analysis of the relation- ship between emotional intelligence and health. Personality and Individual Differences, 49, 554-564. http://dx.doi.org/10.1016/j.paid.2010.05.029

Mayer, J. D., Salovey, P., Caruso, D. R., \& Sitarenios, G. (2003). Measuring emotional intelligence with the MSCEIT V2.0. Emotion, 3, 97-105.

Mayer, J. D., Caruso, D. R., \& Salovey, P. (1999). Emotional intelligence meets traditional standards for an intelligence. Intelligence, 27, 267-298.

Mayer, J. D., \& Salovey, P. (1997). What is emotional intelligence? In P. Salovey \& D. Sluyter (Eds). Emotional development and emotional intelligence: Implications for educators (pp. 3-31). New York: Basic Books.

Montgomery, D. C., Peck, E. A., \& Vining, G. G. (2001). Introduction to Linear Regression Analysis. 3rd Edition, New York, New York: John Wiley \& Sons.

Moon, A., \& Berenbaum, H. (2009). Emotional awareness and emotional eating. Cognition and Emotion, 23(3), 417-429.

National Heart, Lung and Blood Institute. National Institutes of Health. Morbidity and Mortality. (2012). Chart Book on Cardiovascular, Lung and Blood Diseases. Retrieved May 25, 2012 from http://www.nhlbi.nih.gov/resources/docs/2012_ChartBook.pdf

O'Brien, R. M. (2007). A Caution Regarding Rules of Thumb for Variance Inflation Factors. Quality and Quantity, 41(5), 673-690.

Orth-Gomér, K., \& Leineweber, C. (2005). The Stockholm Female Coronary Risk Study. Multiple stressors and coronary disease in women. Biological Psychology, 69, 57-66.

Orth-Gomér, K., Wamala, S. P., Horsten, M., Schenk-Gustafsson, K., Schneiderman, N., \& Mittleman, M. A. (2000). Marital stress worsens prognosis in women with coronary heart disease: The Stockholm Female Coronary Risk Study. JAMA, 284, 3008-3014.

Panagiotakos, D. B., Pitsavos, C., Chrysohoou, C., Stefanadis, C., \& Toutouzas, P. (2002). Risk stratification of coronary heart disease in Greece: final results from the CARDIO2000 Epidemiological Study. Preventive Medicine, 35(6), 548-556.

Payne, W. L. (1986). A study of emotion: Developing emotional intelligence; Self-integration; relating to fear, pain and desire. Dissertation Abstracts International, 47, 203A.

Pennebaker, J. W. (1995). Emotion, disclosure, and health. Washington, DC: American Psychological Association.

Petrides, K. V., \& Furnham, A. (2001). Trait emotional intelligence: psychometric investigation with reference to established trait taxonomies. European Journal of Personality, 15, 425-448.

Reichenberg, A., Yirmiya, R., Schuld, A., Kraus, T., Haack, M., Morag, A., \& Pollmacher, T. (2001). Cytokine-associated emotional and cognitive disturbances in humans. Archives of General Psychiatry, 58, 445-452.

Roncaglioni, M. C., Santoro, L., D'Avanzo, B., Negri, E., Nobili, A., Ledda, A., ... Feruglio, G. A. (1992). Role of family history in patients with myocardial infarction. An Italian case-control study. GISSI-EFRIM investigators. Circulation, 85, 2065-2072.

Rozanski, A., Blumenthal, J. A., \& Kaplan, J. (1999). Impact of Psychological Factors on the Pathogenesis of Cardiovascular Disease and Implications for Therapy. Circulation, 99, 2192-2217.

Rozanski, A., Blumenthal, J. A., Davidson, K. W., Saab, P., \& Kubzansky, L. D. (2005). The epidemiology, pathophysiology, and management of psychosocial risk factors in cardiac practice: the emerging field of behavioral cardiology. Journal of American College of Cardiology, 45(5), 637-651.

Saxena, P., Pandey, T., Dubey, A., Pratap, S., \& Pandey, R. (2012). Differential Affective Profile of Patients with Diabetes and Coronary Artery Disease. SIS Journal of Projective Psychology \& Mental Health, 19, 
137-149.

Scanlon, P. J., Faxon, D. P., Audet, A. M., Carabello, B., Dehmer, G. J., Eagle, K. A., ... Smith, J. (1999). ACC/AHA Guidelines for Coronary Angiography: Executive Summary and Recommendations: A Report of the American College of Cardiology/American Heart Association Task Force on Practice Guidelines (Committee on Coronary Angiography). Developed in collaboration with the Society for Cardiac Angiography and Interventions. Circulation, 99, 2345-2357.

Schutte, N. S., Malouff, J. M., Thorsteinsson, E. B., Bhullar, N., \& Rooke, S. E. (2007). A meta-analytic investigation of the relationship between emotional intelligence and health. Personality and Individual Differences, 42, 921-933.

Simon, A. (2012). Distribution of coronary risk in the population. La revue du praticien, 62(6), 771-775.

Sirois, B. C. \& Burg, M. M. (2003). Negative emotion and coronary heart disease. A review. Behavior Modification, 27(1), 83-102.

Sousa, A. G., Selvatici, L., Krieger, J. E., \& Pereira, A. C. (2011). Association between genetics of diabetes, coronary artery disease, and macrovascular complications: exploring a common ground hypothesis. The Review of Diabetic Studies, 8(2), 230-244. http://dx.doi.org/10.1900/RDS.2011.8.230

Steptoe, A. (2000). Psychosocial factors in the development of hypertension. Annals of Medicine, 32, 371-375.

Tindle, H. A., Chang, Y., Kuller, L. H., Manson, J. E., Robinson, J. G., Rosal, M. C., .. Matthews, K. A. (2009). Optimism, cynical hostility, and incident coronary heart disease and mortality in the Women's Health Initiative. Circulation, 120, 656-662. http://dx.doi.org/10.1161/CIRCULATIONAHA.108.827642

Tsaousis, I., \& Nikolaou, I. (2005). Exploring the Relationship between Emotional Intelligence and Physical and Psychological Health. Stress \& Health, 21, 77-86. http://dx.doi.org/10.1002/smi.1042

Tunstall-Pedoe, H. (2001). "Coronary heart disease" is not tautologous. BMJ, 323, 695.

Urry, H. L., \& Gross, J. J. (2010). Emotion regulation in older age. Current Directions in Psychological Science, $19,352-357$.

Watkins, L. O. (2004). Epidemiology and burden of cardiovascular disease. Clinical Cardiology, 27(6), III2-6.

Weber-Hamann, B., Hentschel, F., Kniest, A., Deuschle, M., Colla, M., Lederbogen, F., \& Heuser, I. (2002). Hypercholesteremic depression is associated with increased intra-abdominal fat. Psychosomatic Medicine, 54, 274-277.

Wilson-Barnett, J. (2008). Alleviating stress for hospitalized patients. Applied Psychology, 33(4), 494-503.

World Health Organisation. (1998). Obesity - preventing and managing the global epidemic. Report of a WHO Consultation on Obesity. WHO, Geneva.

Zhang, Y., Hu, G., Yuan, Z., \& Chen, L. (2012). Glycosylated hemoglobin in relationship to cardiovascular outcomes and death in patients with type 2 diabetes: a systematic review and meta-analysis. PLoS One, 7(8), e42551. http://dx.doi.org/10.1371/journal.pone.0042551

\section{Copyrights}

Copyright for this article is retained by the author(s), with first publication rights granted to the journal.

This is an open-access article distributed under the terms and conditions of the Creative Commons Attribution license (http://creativecommons.org/licenses/by/3.0/). 